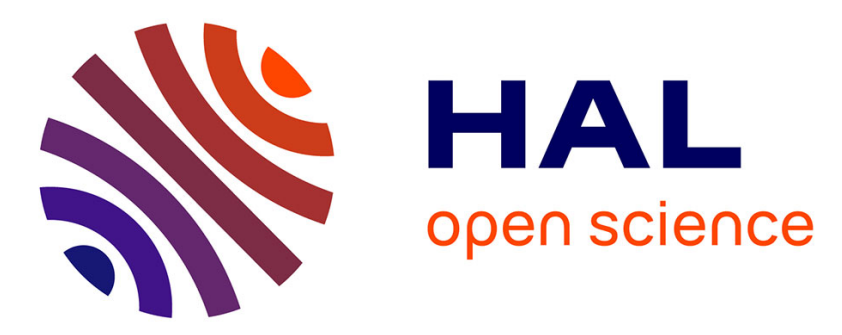

\title{
Impact of non-systematic electric vehicle charging behaviour on a distribution substation
}

Felipe Gonzalez, Marc Petit, Yannick Perez

\section{To cite this version:}

Felipe Gonzalez, Marc Petit, Yannick Perez. Impact of non-systematic electric vehicle charging behaviour on a distribution substation. 2019 IEEE PES Innovative Smart Grid Technologies Europe, Sep 2019, Bucharest, Romania. 10.1109/ISGTEurope.2019.8905710 . hal-02283344

\section{HAL Id: hal-02283344 \\ https://hal.science/hal-02283344}

Submitted on 10 Sep 2019

HAL is a multi-disciplinary open access archive for the deposit and dissemination of scientific research documents, whether they are published or not. The documents may come from teaching and research institutions in France or abroad, or from public or private research centers.
L'archive ouverte pluridisciplinaire HAL, est destinée au dépôt et à la diffusion de documents scientifiques de niveau recherche, publiés ou non, émanant des établissements d'enseignement et de recherche français ou étrangers, des laboratoires publics ou privés. 


\section{Impact of non-systematic electric vehicle charging behaviour on a distribution substation}

\author{
Felipe Gonzalez Venegas and Marc Petit \\ GeePs | Group of electrical engineering - Paris \\ CNRS, CentraleSupélec, Univ. Paris-Sud, \\ Université Paris-Saclay, Sorbonne Université \\ Gif-sur-Yvette, France \\ felipe.gonzalezvenegas@centralesupelec.fr
}

\author{
Yannick Perez \\ Laboratoire de Génie Industriel \\ CentraleSupélec \\ Gif-sur-Yvette, France
}

\begin{abstract}
Massive integration of electric vehicles (EV) into power systems will pose significant challenges, in particular to distribution systems. Additional peak demand by EV charging can induce congestion or voltage issues, which would require costly infrastructure investments. However, these impacts can be reduced by using smart charging mechanisms. The impacts of $\mathrm{EV}$ charging and the efficacy of smart charging algorithms will depend on user behavior (namely travel and charging patterns). This study analyses the impact of non-systematic EV charging on base load, at the HV/MV substation level, and on smart charging potential. Case studies on realistic substations, based on real travel and grid data from France, exemplify the results.
\end{abstract}

Index Terms-Power distribution, Electric vehicles, Electric vehicle charging

\section{INTRODUCTION}

Environmental constraints are pushing the electrification of the transport sector, coming from the need to reduce greenhouse gas emissions to fight climate change and the reduction of local air pollution. Electric vehicles (EVs) can help reduce $\mathrm{CO} 2$ emissions as well as local air pollutants such as nitrous oxides and particulate matter. For these reasons, national and local entities promote the adoption of EVs, with nations having announced the ban of sales of combustion engine cars, like Norway by 2025 or India by 2030 .

The massive integration of EVs into power systems will present great challenges and opportunities in particular to power distribution systems, which is where most EVs will be connected. Simultaneous EV charging can increase peak load, create local congestion or voltage issues. To address these issues, distribution system operators (DSO) will need to reinforce the grid, requiring costly investments. However, EVs can be a source of flexibility by delaying or adapting the charging process according to the user's or the power system requirements (smart charging) or even be used as a mobile storage resource and give back power to the grid (V2G). Thus, in congested distribution networks, adding smartly managed EVs could reduce or delay the required investments, and could be financed for this social contribution like the Art. 199 of the French Energy Law rules it [1].
Studies have analyzed the impacts of EV integration on distribution grids, considering various charging strategies. These strategies can be classified in:

- Uncoordinated: the charging process starts as soon as the EV is connected (for example, when they arrive at home for residential charging) [2].

- Time-of-Use (ToU): the charging process is scheduled during off-peak tariff periods, thus resulting in lower charging cost for the user [3].

- Coordinated: an algorithm (either centralized or decentralized) coordinates the charging process with a given objective, which can provide value to the user, the distribution (local) system or the transmission (nationwide) system [4] [5]. At the distribution level, coordinated EVs can reduce asset overloading or optimize the load curve (load shaping) [6].

Uncoordinated charging in residential neighborhoods can produce overloading of feeders or transformers, as the charging process coincides with base peak load. ToU charging can displace demand to off peak hours, but it can create higher peaks on electricity demand due to the synchronization of the EV charging at the beginning of the off-peak period. Coordinated, or smart, charging can help reduce the impact on distribution grids, with low to no impact on EV users.

Most studies have focused their analyses on residential low voltage grids, with users charging their EV every night. However, these assumptions do not consider different charging behaviors from actual EV users, in particular the fact that they might not plug-in their vehicle every night, as it has been brought out by a recent study [7], and by experts opinions. Charging at night as a routine is linked with 16-24 $\mathrm{kWh}$ batteries. Due to the small size of it, charging at night is the adequate charging behavior. As the current battery size is around $40 \mathrm{kWh}$ or more, charging behavior is evolving.

The present paper analyzes the impact of non-systematic night charging behavior on a distribution grid and on the flexibility potential for smart charging.

This research benefits from the support of the Chair "PSA Peugeot Citroën Automobile: Hybrid technologies and Economy of Electromobility", led by CentraleSupélec and ESSEC, and sponsored by Groupe PSA 
The paper is organized as follows: Section II describes the simulation model. Then, the case studies are presented in Section III, main results in Section IV, and finally conclusions are made in Section V.

\section{SIMULATION MODEL}

A multi-agent EV model has been implemented in Python. For the sake of simplicity and to capture the bigger effect of mobility on distribution systems, each EV is simulated independently, doing one commute every day on weekdays and another trip each day on weekends, characterized by a roundtrip distance $\left(d_{r t}\right)$, a departure time and an arrival time.

Commuting distance is given by a lognormal distribution derived from a survey conducted by the French government in 2008 [8] (with a mean one-way distance of $19.7 \mathrm{~km}$ ). Arrival and departure times are given by a normal distribution, following the methodology presented in [9]. The values for the statistical distributions are shown in Table I.

We defined two plug-in behaviors: (i) systematic, where EVs are plugged in every night, and (ii) non-systematic, where EVs are plugged if the state of charge $\left(S O C_{d}\right)$ of the EV is not enough to carry out the next expected round-trip. This is shown in (1), where Batt represents the battery size $(40 \mathrm{kWh}$ in the study), $\epsilon$ the electric driving efficiency $(0.20 \mathrm{kWh} / \mathrm{km})$, and $\chi$ a range anxiety factor, RAF (initially set at 1.5 ). Additionally, the charging process is forced on Sundays, to simulate that users will want their EVs fully charged for the upcoming week. For sake of simplicity, simulations were carried out using an uncoordinated charging strategy.

TABLE I. PARAMETERS OF STATISTICAL DISTRIBUTIONS

\begin{tabular}{|c|c|c|c|}
\hline Parameter & Distribution & Mean & $\begin{array}{c}\text { Standard } \\
\text { deviation }\end{array}$ \\
\hline One-way distance $[\mathrm{km}]$ & Lognormal & 2.75 & 0.736 \\
\hline Departure (weekday) $[\mathrm{h}]$ & Normal & 8 & 2 \\
\hline Arrival (weekday) $[\mathrm{h}]$ & Normal & 18 & 2 \\
\hline Departure (weekend) $[\mathrm{h}]$ & Normal & 8 & 2 \\
\hline Arrival (weekend) $[\mathrm{h}]$ & Normal & 16 & 8 \\
\hline
\end{tabular}

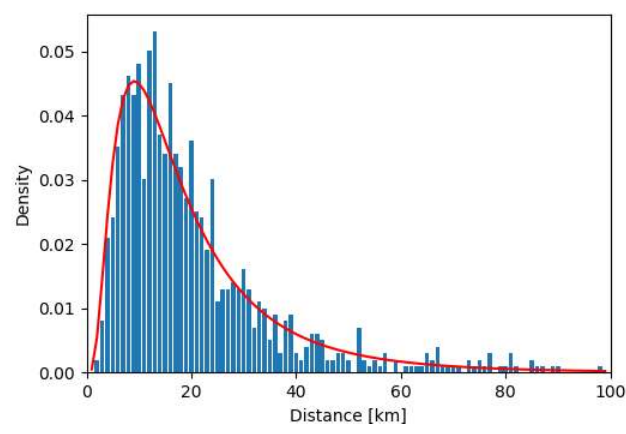

Figure 1. Lognormal distribution for one-way distance, and histogram for 1000 points.

$$
\text { Plug in if: } S_{O} C_{d} \cdot B a t t \leq d_{r t} \cdot \epsilon \cdot \chi
$$

\section{CASE STUDIES}

\section{A. Base case}

A base case to analyze the main trends arising from nonsystematic plug-in behavior was simulated with an uncoordinated charging strategy. It considers $1000 \mathrm{EVs}$ with 40 $\mathrm{kWh}$ battery capacity, charging with a $3.7 \mathrm{kVA}$ charger, and fed by a single HV/MV substation. Simulations were carried out for 8 consecutive days (from Monday to Monday of the following week).

\section{B. Urban and rural substations}

Two case studies of realistic French substations were carried out. The first substation is located in the Paris suburbs and the second one is located in a rural area in the south of France. Using data of commuting travel patterns for these areas from the French census of 2015 [10], distributions of distances corresponding to urban and rural commuting travels were derived for the considered substations, shown in Fig. 2. Urban commuters have shorter mobility requirements, with a mean one-way distance of $8.4 \mathrm{~km}$, whereas rural commuters do longer commutes, with a mean one-way distance of $24.6 \mathrm{~km}$.

The case studies consider a bold scenario of $100 \%$ EV penetration, consisting on $22530 \mathrm{EVs}$ in the urban substation and 9536 EVs in the rural substation. The case studies were carried out for the week of peak base load in 2018. Profiles of base load were derived using public data of annual electricity consumption and aggregated national consumption profiles per type of customer [11]. Technical characteristics of the substations are presented in Table II. Simulations have been done with the hypothesis of a 0.95 power factor.

TABLE II. PARAMETERS OF THE SUBSTATIONS

\begin{tabular}{|c|c|c|}
\hline Substation & Capacity [MVA] & Peak Load [MW] \\
\hline Urban (Paris Suburb) & $3 * 36$ & 81.1 \\
\hline Rural (South of France) & $2 * 20$ & 20.2 \\
\hline
\end{tabular}

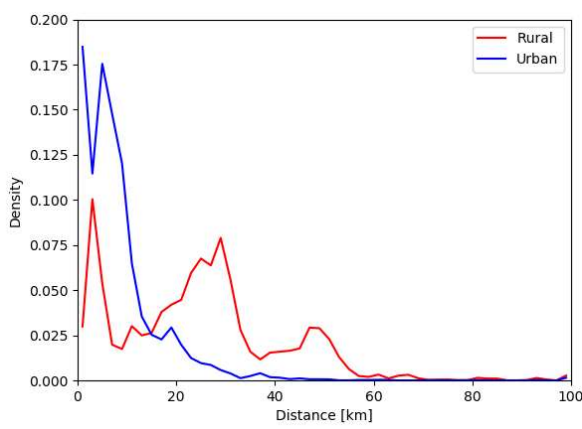

Figure 2. Distribution of one-way commute distance for the two realistic cases. 


\section{RESULTS}

\section{A. Base case}

1) EV load: Fig. 3 shows the EV load of 1000 EVs with an uncoordinated charging, with a systematic and non-systematic plug-in behavior. A systematic charging represents around $1400 \mathrm{~kW}$ of additional load, which can be simultaneous with the evening peak $(7 \mathrm{pm})$ of residential consumption. This represents a coincidence factor of 0.4 , meaning that not all EVs will be charging at the same time (this 0.4 ratio is commonly recommended in France for the sizing of an EV charging installation in a collective residential building).

A non-systematic plug-in behavior can reduce the EV peak load during weekdays but can create greater additional peak load during the weekend (at over $2500 \mathrm{~kW}$, with an impact on the infrastructure sizing for a collective residential building). Nonsystematic plug-in behavior also reduces the flexibility potential for smart charging (given by the orange line in Fig. 3). Since EVs are not connected every day, and when they are, they need to charge a higher amount of energy, the possibility of displacing the load gets reduced.

2) Flexibility storage potential: The flexibility storage potential considering V2G capabilities was computed for each $\mathrm{EV}$, as shown in Fig. 4 (example for one EV). The area within the upper and lower storage limits bound the possible charging trayectories that the EV could follow using smart charging or V2G (uncoordinated charging follows the upper storage limit).

The aggregated flexible storage potential for $1000 \mathrm{EVs}$, with respect to the mean charging trajectory for both plug-in behaviors is shown in Fig. 5. The systematic behavior has important flexible storage potential, mostly for downward flexibility (energy injection). This is because the average mobility needs are low and EVs are connected with a high SOC (mean SOC at arrival of $80.3 \%$ ). On the contrary, the nonsystematic plug-in behavior has significantly lower flexible potential (up and down), given by the lower number of connected EVs, except on Sunday's evenings for upwards flexibility. At the same time, the average SOC at arrival is lower $(37,7 \%)$, requiring more energy per charging session.

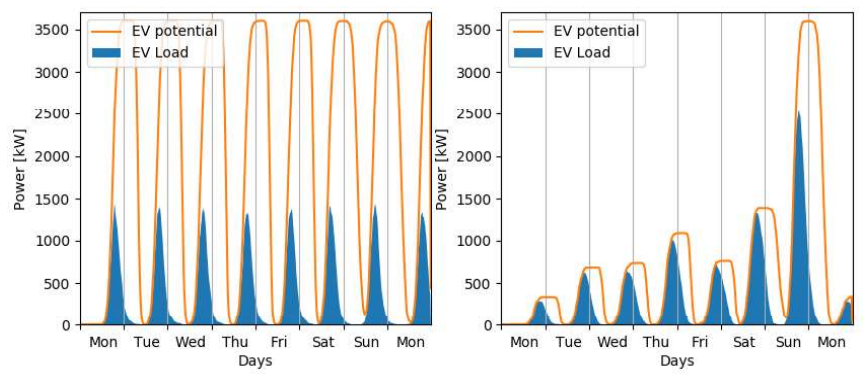

Figure 3. EV load from uncoordinated charging, with a systematic (right) and non-systematic (left) plug-in behavior.

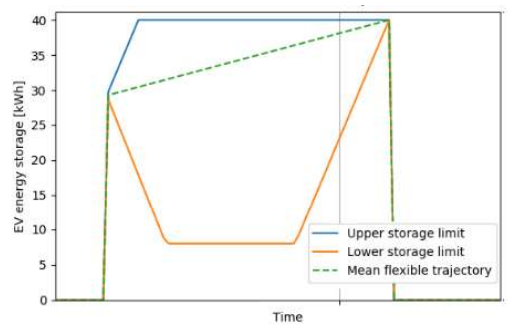

Figure 4. Flexible storage potential for one EV in a given charging session.

3) Impact of battery size: EV battery sizes are increasing, allowing for greater drive range for users. For example, the Renault Zoe passed from a $22 \mathrm{kWh}$ to a $41 \mathrm{kWh}$ battery pack with its 2016 model and the new Peugeot 208 has been announced with a $50 \mathrm{kWh}$ battery. This trend is expected to continue, with an increase of battery sizes around $50 \%$ by 2030 (estimates by the IEA [12]).

A sensibility analysis of the impact of the battery size when considering a non-systematic plug-in behavior was carried out, for three battery sizes: small $(24 \mathrm{kWh})$, medium $(40 \mathrm{kWh})$ and large $(60 \mathrm{kWh})$

Fig. 6 shows the number of charging sessions per week for different battery sizes. It can be seen that increasing the size of the battery reduces the number of charging sessions required per week. While $27 \%$ of EV users will need to recharge every day with a $24 \mathrm{kWh}$ battery, this proportion falls to $4 \%$ with a $60 \mathrm{kWh}$ battery pack. On the other hand, $42 \%$ of users need to charge only once or twice per week with a small battery pack, which in turns rises up to $81 \%$ with a large battery pack, with $60 \%$ only needing to charge once per week.

With increasing battery capacity, charging power will also need to increase to keep charging times reasonable for EV users. A $3.7 \mathrm{kVA}$ charger would take more than 13 hours to charge $80 \%$ of a $60 \mathrm{kWh}$ battery pack, which might encourage users to have chargers with higher power in order to reduce their charging time. However, single-phase grid connection in individual households limits the charging power (presently EVSE above $7.4 \mathrm{kVA}$ are only for 3-phases connection). This effect might lead to higher peak loads in the distribution grid.

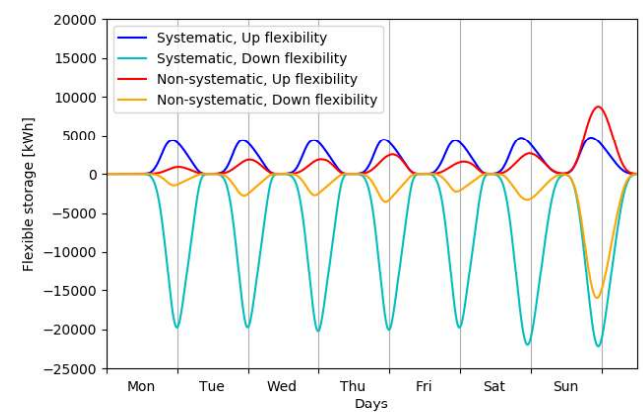

Figure 5. Up and down flexible storage for $1000 \mathrm{EVs}$ with a systematic and non-systematic plug-in behavior. 


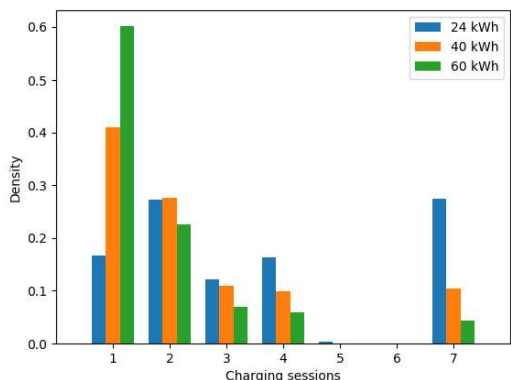

Figure 6. Distribution of the number of charging sessions per week, according to the battery size.

4) Sensitivity of the range anxiety factor: A sensitivity analysis was carried out with respect of the value of the range anxiety factor used (RAF) in the model. Fig. 6 shows the distribution of the number of charging sessions per week, as the $\mathrm{RAF}$ increases from 1.5 to 2.5 . As expected, as the RAF increases, the users will charge more often their EVs.

However, the effect is limited and over $60 \%$ of EVs will only need to be charged at most 2 times a week, and only $18 \%$ charging every day with a RAF of 2.5.

\section{B. Urban and rural substations}

Understanding driving and charging behavior is key to analyze the impacts of EVs in power distribution grids, as well as to implement successful smart charging systems. In this case, mobility requirements are greatly influenced by the characteristics of the region, in this case whether it is an urban or a rural zone. As shown in the previous section, rural dwellers have significant longer commutes than urban dwellers. Therefore, their charging requirements will be different.

Fig. 7 shows the number of charging sessions per week for the urban and rural substations, when considering a nonsystematic plug-in behavior by EV users. It can be seen that higher mobility requirements from rural dwellers leads to higher plug-in rates. Indeed, $51 \%$ of rural dwellers plug-in every day, whereas only $4 \%$ does on the Parisian suburb. On the contrary, over $58 \%$ of the habitants of the Parisian suburb would need to plug-in only once a week, whereas this happens only for $19 \%$ of rural EV users.

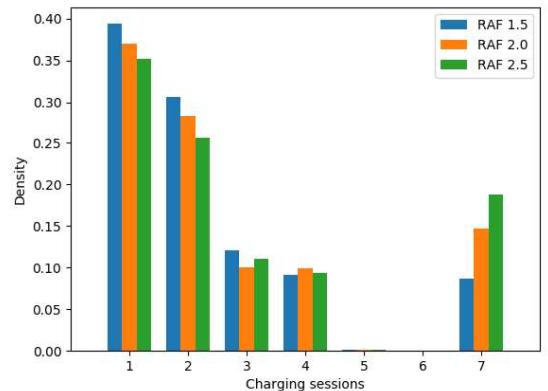

Figure 7. Distribution of the number of charging sessions per week, according to the range anxiety factor (RAF).

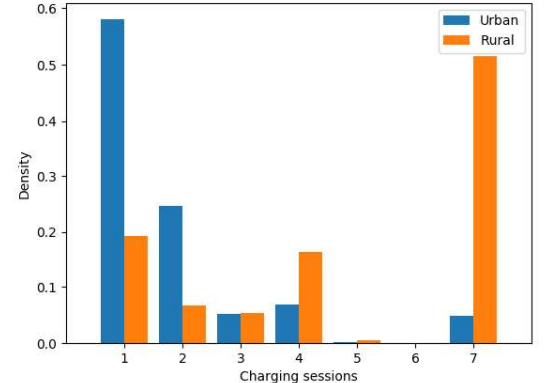

Figure 8. Distribution of the number of charging sessions per week, for urban and rural substations.

This behavior will have an impact on the aggregated EV load and on the total load on the substation. Fig. 8 and Fig. 9 show the total load at the substations for an uncoordinated charging strategy, with systematic and non-systematic plug-in behavior.

In the case of the urban substation, uncoordinated charging with systematic plug-in behavior (right in Fig. 8) produces an overload in the substation capacity, though for short durations. This is because EV load coincides with the afternoon peak load. Non-systematic charging behavior manages to displace a significant part of EV charging to the weekend, thus reducing the peak load during weekdays. This is beneficial at the substation level, since weekends present a lower base load, and can accommodate the additional demand. However, it should be noted that the additional EV demand on Sundays could create constraints downstream from the substation, especially in residential low voltage grids where clusters of EVs with limited flexibility might be found.

In the case of the rural substation, total load also exceeds substation capacity during weekdays, driven largely by EV charging (Fig. 10). In this substation, EV load represents over $55 \%$ of the overall peak load. Non-systematic plug-in behavior has minor impact in this substation, as a larger percentage of drivers recharge their vehicles every day. Even though the weekday peak load is reduced and some part of the EV charging is displaced to the weekends, this effect is not enough and substation overloading still occurs on Tuesday and Thursday of the simulated week.
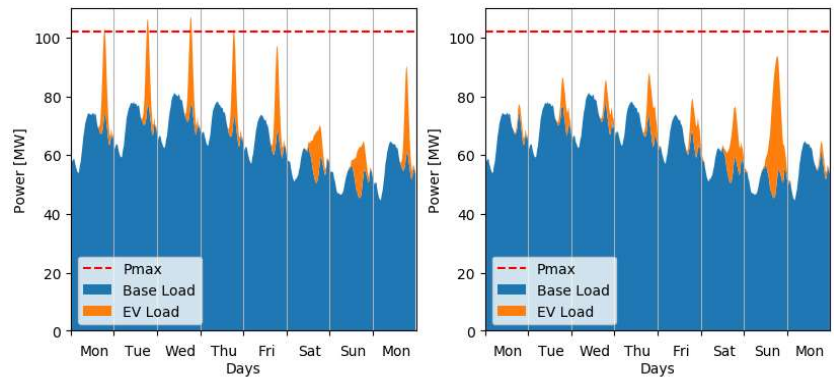

Figure 9. Total load for the urban substation, considering a systematic (left) and non-systematic (right) plug-in behavior. 

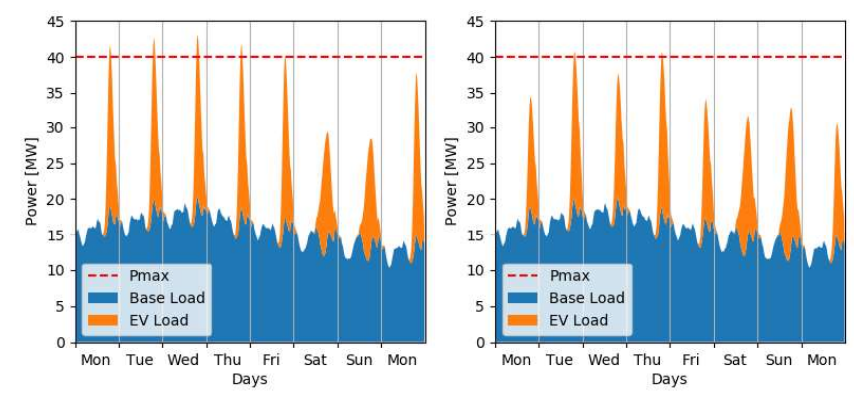

Figure 10. Total load for the rural substation, considering a systematic (left) and non-systematic (right) plug-in behavior.

Globally, we observe that both substations have a large margin to accommodate additional EV load if properly managed. The simulations were made with an extreme scenario of $100 \% \mathrm{EV}$ penetration, with every user having the same driving and charging behavior. Even with these parameters, substation overloading occurred only for a few hours during the week with the higher peak load of the year. However, it must be mentioned that such high peaks would reinforce the thermal stress of the transformers with larger variations along the day (the smoother the temperature, the better it is for the life span). It will also reduce the capability of back-up operation between two transformers (usually in case of transformer fault, its MV busbar is, totally or partially, transferred to the neighbor one).

Nevertheless, additional EV load is significant and could create issues (congestion or voltage) downstream from the substation. EV load can significantly alter the demand profile at the daily and weekly level.

\section{CONCLUSIONS}

The massive integration of EVs into distribution systems will present significant challenges. To accurately analyze the impacts of EV grid integration, driving and charging patterns should be taken into account. This study analyzed both driving requirements, by means of study cases on rural and urban regions in France using real mobility data, as well as charging behavior, by means of the comparison of systematic and nonsystematic plug-in behavior.

Non-systematic plug-in behavior can displace part of the charging towards the weekend, thus reducing additional load during weekdays. This effect can be exacerbated by the industry trend to increase battery capacity, thus allowing EV users to charge fewer times a week, as well as by EV oriented electricity plans with lower prices during the weekend.

At the HV/MV substation level, this behavior is beneficial, as it effectively displaces part of the load to low demand periods. However, it may create issues downstream of the substation where clusters of EVs with high energy requirements might be found, which need to be further studied.

Finally, non-systematic plug-in behavior can be prejudicial to smart charging or $\mathrm{V} 2 \mathrm{G}$ mechanisms, as the flexibility potential of EV charging process diminishes. As EVs are connected fewer times a week and have higher energy requirements per session, the potential to displace or delay part of the charging process gets reduced. This could be critical for EV aggregators that offer ancillary services to the grid, such as frequency regulation or energy arbitrage, especially if they make use of V2G technology. Aggregators might need to find ways to encourage EV users to plug-in their vehicles to make them available for the proposed grid services.

Understanding driving and charging behavior will be critical to assess the impacts and flexibility potential of EVs. Several factors will influence them, such as EV characteristics (battery size), charging infrastructure (power, home/work availability), electricity tariffs and user preferences (range anxiety, mobility requirements). Further work should be carried out to analyze the impacts of these aspects on EV grid integration.

\section{REFERENCES}

[1] French government. Law 2015-992 for the energy transition and green growth, article 199. 2015 [Online] Available : https://www.legifrance.gouv.fr/eli/loi/2015/8/17/2015-992/jo/texte

[2] M. Neaimeh, R. Wardle, A. M. Jenkins, J. Yi, G. Hill, P. F. Lyons, Y. Hübner, P. T. Blythe and P. C. Taylor, "A probabilistic approach to combining smart meter and electric vehicle charging data to investigate distribution network impacts," Applied Energy, vol. 157, pp. 688-698, 1112015 .

[3] N. Leemput, F. Geth, J. Van Roy, J. Büscher and J. Driesen, "Reactive power support in residential LV distribution grids through electric vehicle charging," Sustainable Energy, Grids and Networks, vol. 3, pp. 24-35, 92015

[4] F. Gonzalez Venegas, M. Petit and Y. Perez, "Electric vehicles as flexibility providers for distribution systems. A techno-economic review", unpublished, presented at the $25^{\text {th }}$ International Conference on Electricity Distribution, Madrid, 2019.

[5] C. Eid, P. Codani, Y. Perez, J. Reneses, R. Hakvoort, "Managing electric flexibility from Distributed Energy Resources: A review of incentives for market design" Renewable and Sustainable Energy Reviews, vol 64 pp 237-247, 2016

[6] E. Ramos Muñoz, G. Razeghi, L. Zhang and F. Jabbari, "Electric vehicle charging algorithms for coordination of the grid and distribution transformer levels," Energy, vol. 113, pp. 930-942, 1510 2016.

[7] L. Calearo, "Flexibility procurement by EVs in a Danish active distribution network: Study cases from the island of Bornholm," Masters thesis, DTU, 2018.

[8] INSEE, "Enquête nationale transports and déplacements (ENTD) 2008," 2010 .

[9] O. Borne, "Vehicle-To-Grid and flexibility for electricity systems: from technical solutions to design of business models" Ph.D. disssertation, Université Paris-Saclay, Paris, 2019.

[10] INSEE, "Mobilités professionnelles en 2015: déplacements domicile lieu de travail | Insee," [Online]. Available: https://www.insee.fr/fr/statistiques/3566477.

[11] Enedis, "Enedis Open Data," [Online]. Available: https://data.enedis.fr/explore.

[12] International Energy Agency, "Global EV Outlook 2018," 2018 